\title{
Characterization of $\mathrm{Cu}_{2} \mathrm{ZnSn}(\mathrm{SSe})_{4}$ monograin powders by FE-SEM
}

\author{
F. Neves", V. Livramento", I. Martins ${ }^{*}$, L. Esperto ${ }^{*}$, M. Santos ${ }^{*}$, J.B. Correia ${ }^{*}$, K. Muska ${ }^{* *}$ and T. Holopainen ${ }^{* *}$ \\ LNEG, Laboratório Nacional de Energia e Geologia, Estrada do Paço do Lumiar, 22, 1649-038 Lisboa, Portugal \\ Crystalsol OÜ, Akadeemia tee 15a, 12618, Tallinn, Estonia
}

The design and synthesis of high-efficiency materials to convert solar to electrical energy is an increasingly important research field. Within the photovoltaic technologies, crystalline $\mathrm{Si}$ have an $80 \%$ share while the remaining $20 \%$ are mostly thin film solar cells based on $\mathrm{Cu}(\mathrm{In}, \mathrm{Ga})(\mathrm{S}, \mathrm{Se})_{2}(\mathrm{CIGSSe})$ and $\mathrm{CdTe}[1,2]$. However, the cost, the abundance and the environmental impact of the elemental components cannot be neglected. For these reasons, $\mathrm{Cu}_{2} \mathrm{ZnSnS}_{4}(\mathrm{CZTS}), \mathrm{Cu}_{2} \mathrm{ZnSnSe}_{4}$ (CZTSe) and their solid solutions CZTSSe has attracted much attention recently since they can provide the development of cost competitive solar cells. The CZTS-based solar cells consist of earth abundant and relatively inexpensive elements and represent an environmentally friendly alternative compared to the above mentioned systems [3]. The energy conversion efficiency of the CZTS-based solar cells has increased from $0.66 \%$ in 1996 to $11.1 \%$ recently [4].

The present work shows preliminary results that are related to the characterization of CZTSSe monograin powders by scanning electron microscopy. High purity metal compounds, S and Se powders were used as precursors for the synthesis of the $\mathrm{Cu}_{2} \mathrm{ZnSn}(\mathrm{SSe})_{4}$ monograin powders. The precursor powders were mixed to the desired composition and, additionally, KI was added as a flux material. Afterwards, the powders were blended in a mixer and encapsulated in quartz ampoules. The blended powders were degassed under dynamic vacuum at room temperature, sealed and annealed isothermally between $700{ }^{\circ} \mathrm{C}$ and $780{ }^{\circ} \mathrm{C}$ for a time ranging between $44 \mathrm{~h}$ and $136 \mathrm{~h}$. After synthesis the flux material was removed with deionized water and the powders were sieved into several fractions. The morphology, microstructure and chemical composition of the synthesized powders was obtained with a Philips XL30 field-emission scanning electron microscope (FE-SEM) equipped with a backscattered electron (BSE) detector and an integrated EDAX energy dispersive X-ray spectroscopy (EDS) microanalysis system.

The typical morphology obtained for the CZTSSe powders can be seen in Figure 1. Basically, the particles show a polyhedral morphology with some of them showing a needle shape, i.e. a large shape factor $(\mathrm{L} / \mathrm{D}>>1)$. Moreover, it was also observed a slight increase of the median particle size with the increase of the synthesis temperature. Due to the complexity of the synthesis of CZTSSe monograins, the formation of binary or ternary phases is a common feature [3]. A very good control over the synthesis parameters is then required not only to obtain the desired phase but also to have a tight control over the stoichiometry of the material. Taking this into account, SEM/BSE observations and EDS analysis are two powerful techniques for evaluate the degree of the compositional homogeneity of the CZTSSe monograins. Figure 2 puts in evidence the degree of the homogeneity of the CZTSSe monograins in relation to their size. Overall, and independently of the synthesis conditions, the powder particles consisted predominantly of CZTSSe monograins and, in a much smaller extent, of particles having a $\mathrm{ZnS}$ or $\mathrm{ZnS}(\mathrm{Se})$ core coated by a CZTSSe layer. The presence of undesired phases occurred more frequently in the larger powder particles $(>100 \mu \mathrm{m})$ and the degree of homogeneity was lower for the powders synthesized at lower temperature and for a shorter time. However, when the EDS results obtained for CZTSSe monograins belonging to different size fractions are compared no major variations in the content of the five elements can be inferred.

References

1. Chung I. et al., Nature, 485:486-490, 2012.

2. Mitzi D.B. et al., Sol. Energ. Mater. Sol. Cell., 95:1421-1436, 2011.

3. Muska K., et al., Energy Procedia, 10:203-207, 2011.

4. Todorov T.K., et al., Adv. Energy Mater. doi: 10.1002/aenm.201200348, 2012. 

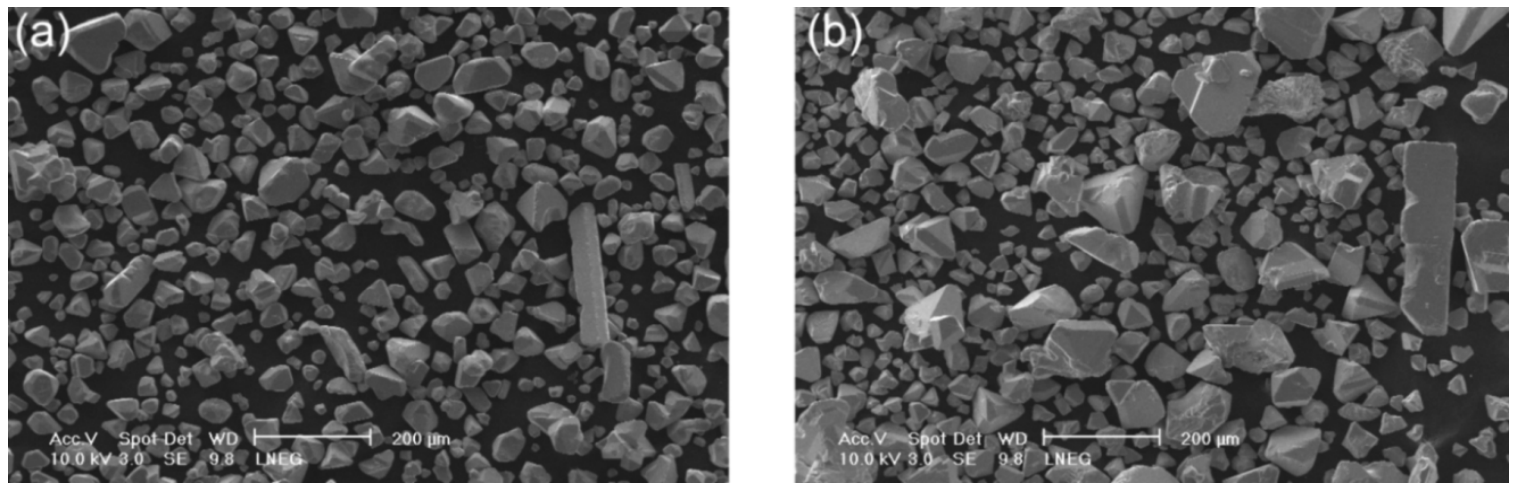

Figure 1. SEM images showing the typical morphology of the CZTSSe powders synthesized at (a) $780{ }^{\circ} \mathrm{C} / 44 \mathrm{~h}$ and (b) $780{ }^{\circ} \mathrm{C} / 136 \mathrm{~h}$.
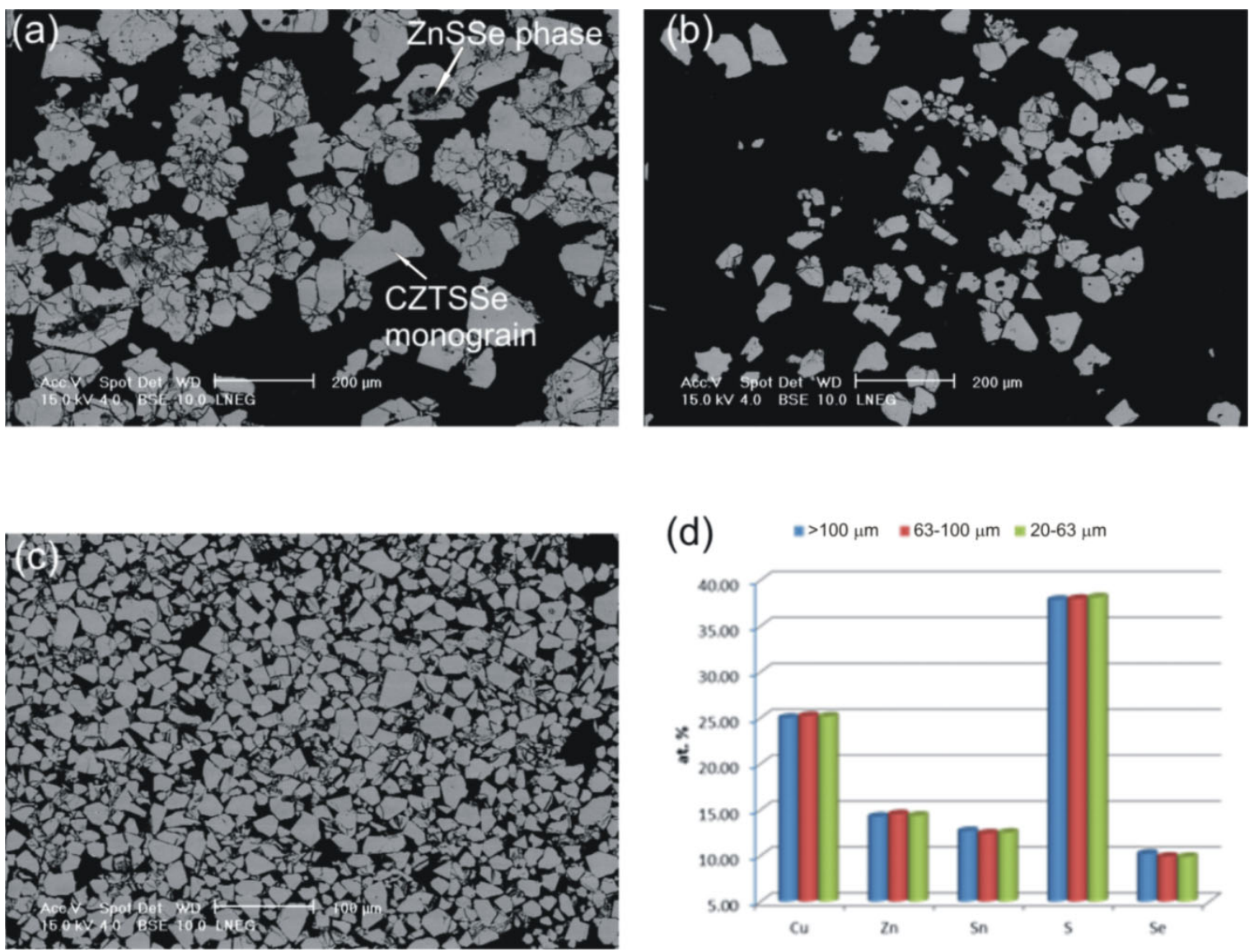

Figure 2. SEM/BSE images showing the typical microstructure of the CZTSSe powders synthesized at $700{ }^{\circ} \mathrm{C} /$ $136 \mathrm{~h}$, corresponding to different sieved fractions: (a) $>100 \mu \mathrm{m}$, (b) 63-100 $\mu \mathrm{m}$, (c) 20-63 $\mu \mathrm{m}$. (d) EDS semiquantitative microanalysis results of the monograin powders. 